\title{
Pelatihan Membuat Toko Online Menggunakan Aplikasi Marketplace Pada Fatayat NU Ciledug
}

\author{
Khoirun Nisa ${ }^{1}$, Rizki Aulianita ${ }^{1}$, Anna Mukhayaroh ${ }^{1, *}$, Syifa Nur Rakhmah ${ }^{1}$, Nu'man \\ Musyaffa $^{1}$ \\ ${ }^{1}$ Fakultas Teknologi Informasi; Universitas Nusa Mandiri, Jl. Jatiwaringin Raya No. 2 Kelurahan \\ Cipinang Melayu, Kecamatan Makasar, Jakarta Timur, telp. (021) 8005722; e-mail: \\ khoirun.khn@nusamandiri.ac.id, rizki.rzk@nusamandiri.ac.id, anna.auh@nusamandiri.ac.id, \\ syifa.snk@nusamandiri.ac.id, numan.nmf@nusamandiri.ac.id \\ * Korespondensi: e-mail: anna.auh@nusamandiri.ac.id
}

Submitted: 21/10/2021; Revised: 08/12/2021; Accepted: 04/01/2022; Published: 31/01/2022

\begin{abstract}
Fathayat Nahdatul Ulama (NU) Ciledug branch is one of the major Islamic organizations in Indonesia under the auspices of Nahdatul Ulama (NU). Most of the members and administrators of this organization are women from the age of 20 to 45 years. The problem with this organization is that some of the board members have trading businesses that are only known by the surrounding environment. By providing E-commerce training, this can be used as a promotional medium by utilizing (Pandemi Akselerasi Perubahan Perilaku Belanja Online)an existing marketplace. Fathayat Nahdatul Ulama (NU) Ciledug is an organization that actively organizes social activities. This is also the reason for the need to hold training on the use of marketplace applications to increase sales so that part of the sales profits can be donated to the social activities carried out.
\end{abstract}

Keywords: Marketplace, Media Promotion, NU

\begin{abstract}
Abstrak
Fathayat Nahdatul Ulama (NU) cabang Ciledug merupakan salah satu organisasi Islam besar di Indonesia yang dinaungi oleh Nahdatul Ulama (NU). Sebagian besar anggota dan pengurus organisasi ini adalah perempuan dari umur 20 tahun hingga 45 tahun. Permasalahan pada organisasi ini adalah beberapa anggota pengurus memiliki usaha dagang yang hanya dikenal oleh lingkungan sekitar. Dengan memberikan pelatihan Ecommerce maka hal tersebut dapat dijadikan media promosi dengan memanfaatkan marketplace yang sudah ada. Fathayat Nahdatul Ulama (NU) Ciledug adalah organisasi yang aktif mengadakan kegiatan-kegiatan sosial. Hal tersebut juga melatarbelakangi perlu diadakannya pelatihan penggunaan aplikasi marketplace untuk meningkatkan penjualan sehingga sebagian keuntungan penjualan dapat disumbangkan pada kegiatan sosial yang dilaksanakan.
\end{abstract}

Kata kunci: Marketplace, Media Promosi, NU

\section{Pendahuluan}

Fathayat Nahdatul Ulama (NU) cabang Ciledug merupakan salah satu organisasi Islam besar di Indonesia yang dinaungi oleh Nahdatul Ulama (NU). Nahdlatul Ulama lahir pada tanggal 31 Januari 1926 sebagai reprensentatif dari ulama tradisionalis, dengan haluan ideologi ahlus sunnah waljamaah tokoh-tokoh yang ikut berperan diantaranya K.H. Hasyim Asy'ari. K.H. Wahab Hasbullah dan para ulama pada masa itu pada saat kegiatan reformasi mulai 
berkembang luas, ulama belum begitu terorganisasi namun mereka sudah saling mempunyai hubungan yang sangat kuat. Perayaan pesta seperti haul, ulang tahun wafatnya seorang kiai, secara berkala mengumpulkan para kiai, masyarakat sekitar ataupun para bekas murid pesantren mereka ya ng kini tersebar luas diseluruh nusantara (Hasyim, 2002).

Didalam Fathayat Nahdatul Ulama (NU) cabang Ciledug juga terdapat perkumpulan ibu-ibu pengajian yang aktif dalam pertemuan dan berbagai kegiatan-kegiatan sosial. Beberapa dari ibu-ibu sudah memiliki usaha dagang dibidang kuliner dan fashion yang memiliku kendala hanya dikenal oleh lingkungan sekitar sehingga terbatasnya promosi yang dilakukan. Tentu saja hal tersebut berdampak pada penjualan dari usaha tersebut.

Coronavirus Disease 2019 (COVID-19) ditemukan pada akhir tahun 2019 tepatnya bulan Desember di Kota Wuhan, Provinsi Huebei, China dan kemudian menyebar ke hampir seluruh dunia. Covid-19 disebabkan oleh betacoronavirus jenis baru yang cenderung mirip SARS-CoV dan MERS-CoV (Levani, Prastya, \& Mawaddatunnadila, 2021).

Pandemi Covid-19 sedikit banyak mengubah tatanan kehidupan di masyarakat. salah satunya dalam hal belanja. Selama pandemi, minat masyarakat mengunjungi dan berbelanja daring atau online mendorong peningkatan nilai transaksi e-commerce. Dibuktikan dengan data sepanjang semester I-2021, transaksi e-commerce tumbuh 63,4 persen menjadi Rp186,7 triliun. Bank Indonesia (BI) memperkirakan hingga akhir tahun 2021 transaksi e-commerce dapat meningkat 48,4 persen sepanjang tahun 2021 menjadi Rp395 triliun (Merdeka, 2021).

Menurut Laudon dan Laudon E- Commerce adalah suatu proses membeli dan menjual produk - produk secara elektronik oleh konsumen dan dari perusahaan ke perusahaan dengan komputer sebagai perantara transaksi bisnis (Laudon \& Laudon, 1998).

Marketplace adalah penggunaan data elektronik dan aplikasi untuk perencanaan dan pelaksanaan konsepsi, distribusi dan harga sebuah ide, barang dan jasa untuk menciptakan pertukaran yang memuaskan tujuan individu dan organisasi (Strauss, J. and Frost, 2001).

Marketplace merupakan media online berbasis internet (web based) tempat melakukan kegiatan bisnis dan transaksi antara pembeli dan penjual. Sedangkan bagi supplier/penjual dapat mengetahui perusahaan-perusahaan yang membutuhkan produk/jasa mereka (Opiida, 2014).

Tujuan dari pengurus membuat usaha salah satunya adalah untuk dapat selalu ikut serta memberikan bantuan dari sebagian hasil keuntungan penjualan dalam kegiatan-kegiatan sosial yang dilakukan. Hal tersebut tentunya adalah hal positif yang perlu kita dukung karena dapat memberikan manfaat besar untuk penerima bantuan dari kegiatan sosial tersebut.

Dosen yang mempunyai kewajiban melaksanakan Tri Dharma Perguruan Tinggi yaitu Pengabdian kepada Masyarakat. Pengabdian kepada masyarakat atau kegaitan pengabdian kepada masyarakat adalah kegiatan yang mencakup upaya-upaya peningkatan kualitas sumber daya manusia antara lain dalam hal perluasan wawasan, pengetahuan maupun peningkatan keterampilan yang dilakukan oleh civas akademika sebagai perwujudan dharma bakti serta 
wujud kepedulian untuk berperan katif meningkatkan kesejahteraan dan memberdayakan masyarakat luas terlebih bagi masyarakat ekonomi lemah.(Indonesia, 2011)

Dosen Universitas Nusa Mandiri memberikan kontribusi dengan memberikan Pelatihan Ecommerce Dengan Membuat Toko Online Menggunakan Aplikasi Marketplace pada Fatayat NU Ciledug. Tujuan pengabdian ingin memberikan pengetahuan dan keterampilan kepada generasi muda dengan memanfaatkan teknologi e-commerce. Materi yang diberikan tentang aplikasi e-commerce dan bagaimana menggunakan e-commerce sehingga dapat memberikan manfaat dan peluang usaha (I.K.A.Purnawan, 2016).

Rata-rata nilai transaksi e-commerce di 2020 mengalami kenaikan di semua kategori produk jika dibandingkan pada 2019. Peningkatan rata-rata nilai transaksi secara konsisten di hampir semua kategori produk, karena pergeseran kebiasaan konsumen untuk berbelanja online. Hal ini sekaligus menunjukkan kepercayaan konsumen pada transaksi digital, meski distribusi belum merata di beberapa wilayah. Bank Indonesia memperkirakan, transaksi ecommerce akan naik hingga 33,2 persen pada 2021. Sebelumnya, pada 2020, kenaikan transaksi masih sebesar 23,3 persen di tengah pandemi.

Lokasi kegiatan dilaksanakan di Jl. H. Mencong, Gg Mekar Jaya, Paninggilan Utara Ciledug - Tangerang. Kegiatan tersebut diharapkan dapat memberikan kontribusi positif sehingga penjualan meningkat.

\section{Metode Pelaksanaan}

Dalam menunjang pelaksanaan kegiatan pengabdian masyarakat ini metode Pengabdian Masyarakat yang digunakan Metode SDLC. Menurut (Sukamto \& Shalahuddin, 2018)mengemukakan bahwa SDLC atau Software Development Life Cycle atau sering disebut juga System Development Life Cycle adalah proses mengembangkan atau mengubah suatu sistem perangkat lunak dengan menggunakan model-model dan metodologi yang digunakan orang untuk mengembangkan sistem-sistem perangkat lunak sebelumnya (berdasarkan best practice atau cara-cara yang sudah teruji baik).

Metode SDLC (Pressmann, 2015) menggunakan metode SDLC (system development life cycle) yaitu Requirment, Design, Implementation, Verification, Maintenance. Pengukuran dilakukan berdasarkan kenaikan traffic pembeli dan transaksi penjualan. 1) Requirement dilakukan pada saat pengumpulan data dan persyaratan yang digunakan untuk pemenuhan kebutuhan. Hal ini digunakan untuk menarik jumlah pembeli yang datang sebelum masa pandemic dan saat terjadi pandemic Covid-19. Sumber yang dijadikan rujukan adalah laporan traffic pembeli dan penjualan. 2) Desain adalah cara dan teknik yang digunakan dalam membuat toko online pada aplikasi marketplace tersebut dengan mudah dan sederhana sehingga dapat menarik minat pengunjung untuk melihat toko online tersebut. 3) Implementation adalah penerapan toko online sebagai salah satu media promosi digital yang dapat digunakan untuk menaikkan traffic pembeli. 4) Verification, merupakan salah satu cara untuk merekam, menyimpan secara terstruktur user yang mengunjungi toko online tersebut. 5) 
Maintenance digunakan untuk menjaga traffic pembeli agar tetap stabil dan penjualan semakin meningkat.

Adapun metode pelatihan dalam mengatasi permasalahan yang telah dijelaskan pada bab sebelumnya yaitu dengan cara pelatihan berupa teknik dan cara pembuatan toko online pada aplikasi marketplace dengan menyampaikan ceramah, tanya jawab serta diskusi. Sedangkan praktikum yang dilakukan berupa teknik simulasi dan uji coba transaksi ditoko online tersebut.

\section{Hasil dan Pembahasan}

Kegiatan pengabdian masyarakat yang dilaksanakan berupa Pelatihan Ecommerce Dengan Membuat Toko Online Menggunakan Aplikasi Marketplace pada Fatayat NU Ciledug, dilaksanakan secara virtual melalui Zoom Meeting. Teknik yang digunakan dalam penyampaian materi melalui Zoom Conference dengan menggunakan alat bantu multimedia berupa laptop yang sudah terkoneksi dengan internet, modul, post test dan pretest.

\subsection{Lokasi Pengabdian Kepada Masyarakat}

Lokasi kegiatan kegiatan pengabdian kepada masyarakat dilaksanakan di kantor Fatayat NU Ciledug, Tangerang. Terlihat pada gambar 1 Gedung Sekretariat Fathayat NU Ciledug.

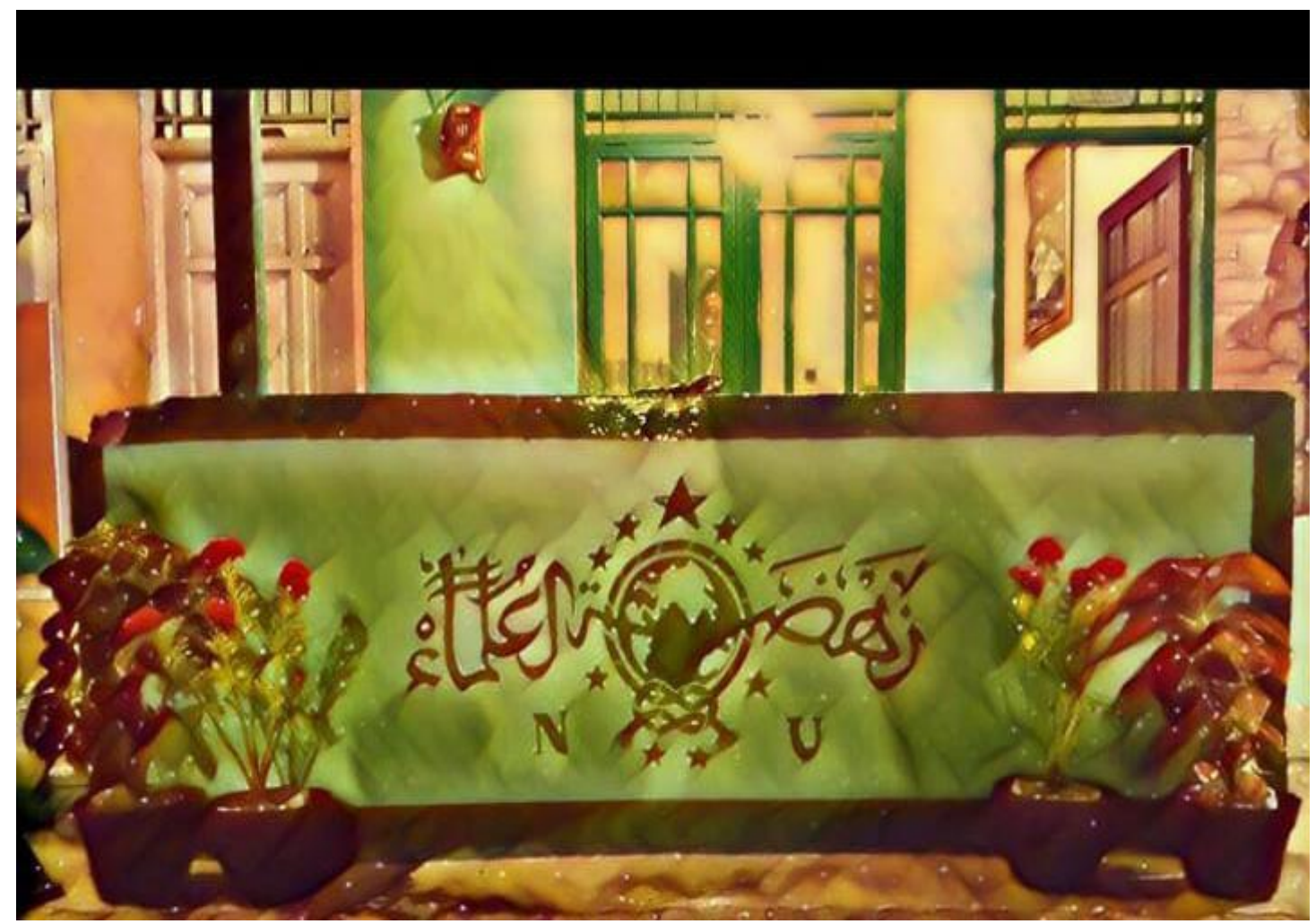

Sumber: Fatayat NU Ciledug (2021)

Gambar 1. Foto Gedung Sekretariat Fathayat NU Ciledug

Pada gambar 2 terlihat beberapa kegiatan dari Fatayat NU Ciledug yang telah dilakukan di lingkungan sekitar. 

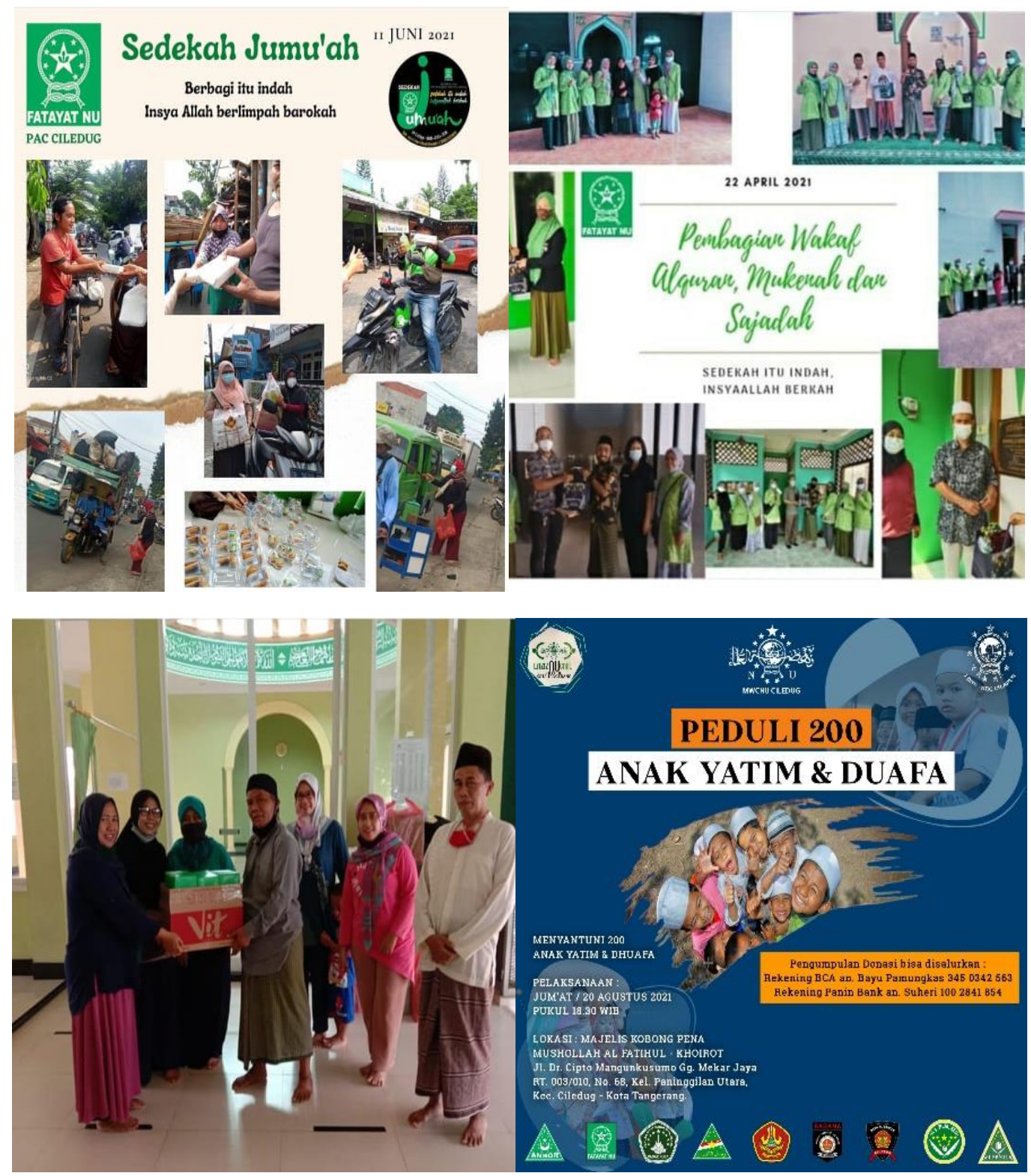

Sumber: Fatayat NU Ciledug (2021)

Gambar 2. Beberapa kegiatan Fatayat NU Ciledug

Permasalahan yang terjadi pada anggota Fatayat NU Ciledug adalah Informasi pengetahuan yang kurang dari pengurus untuk memperluas media promosi usaha dagangnya, Lokasi pemasaran produk yang terbatas hanya diketahui lingkungan sekitar. Solusi yang diberikan adalah dosen-dosen dari Universitas Nusa Mandiri mengadakan pelatihan dengan menerapkan aplikasi marketplace yang sudah ada seperti Shopee dan Tokopedia. Dengan dibuatnya toko online menggunakan aplikasi marketplace maka akan banyak orang mengetahui produk yang dipasarkan. Dampak dari solusi tersebut, para pengurus Fatayat NU Ciledug akan mengikuti perkembangan teknologi dan meningkatkan jangkauan pemasaran menjadi luas sehingga meningkatkan penjualan mereka. 


\subsection{Pelaksanaan Pengabdian Kepada Masyarakat}

Kegiatan pengabdian kepada masyarakat dilaksanakan di kantor Fatayat NU Ciledug pada hari Sabtu, 02 Oktober 2021 berlokasi di Jl. H. Mencong, Gg Mekar Jaya, Paninggilan Utara, Ciledug - Tangerang. Kegiatan pengabdian kepada masyarakat dimulai dari pukul 09.00 sampai dengan pukul 12.00. Pelaksanaan kegiatan pengabdian kepada masyarakat dihadiri peserta berjumlah 20 orang peserta.

Link zoom meeting:

https://zoom.us///98853054472?pwd=Nm5SZUY4Uytad2dicS9YUTI mTjdiQT09

Meeting ID : : 98853054472

Passcode : PM123

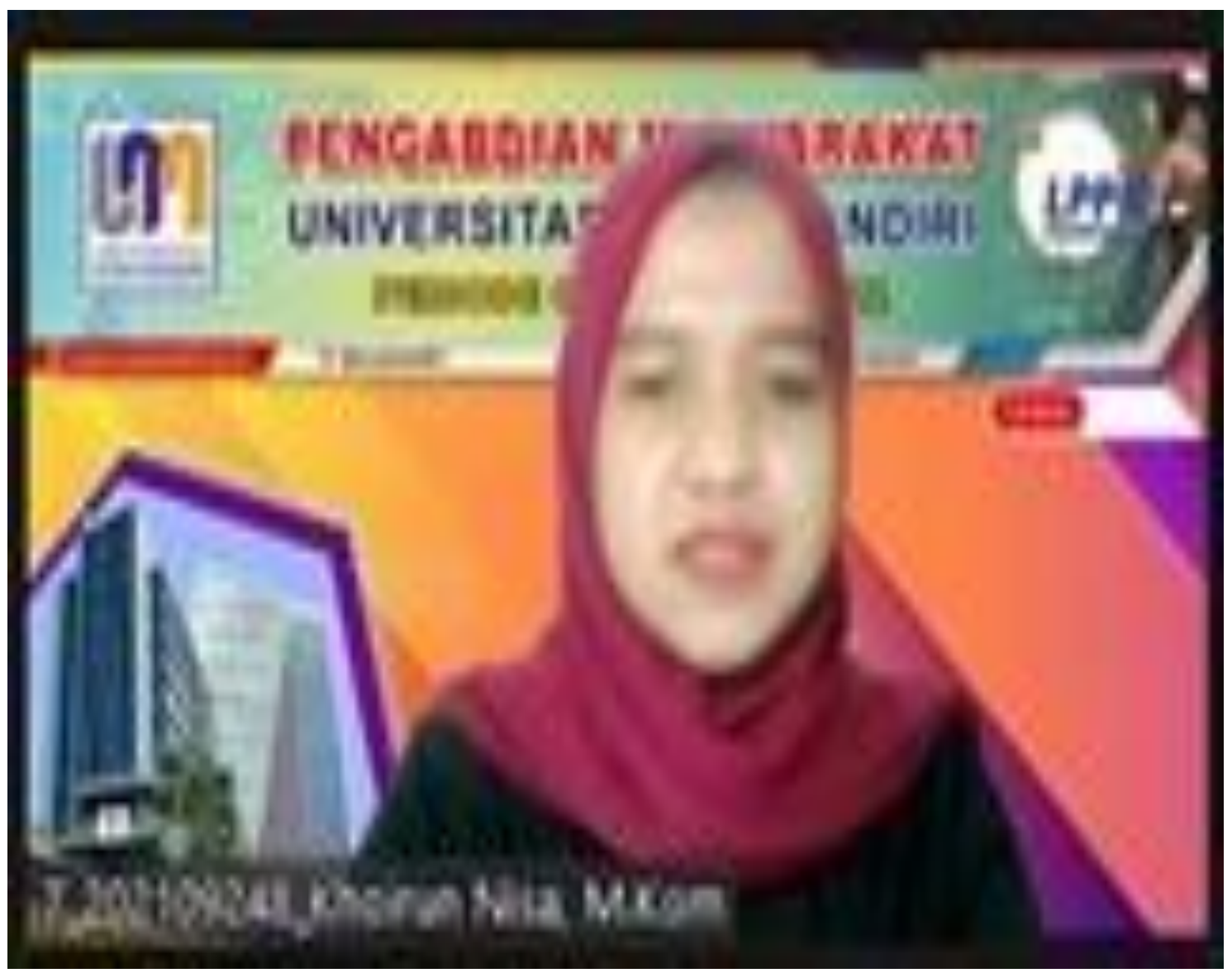

Sumber: Hasil Pelaksanaan (2021)

Gambar 3. Sambutan dari Ketua Pengabdian Masyarakat.

Pada gambar 3 terlihat Ibu Khoirun Nisa, M.Kom selaku ketua pengabdian masyarakat sedang memberikan sambutan pada pelaksanaan pengabdian kepada masyarakat di Fatayat NU Ciledug. 


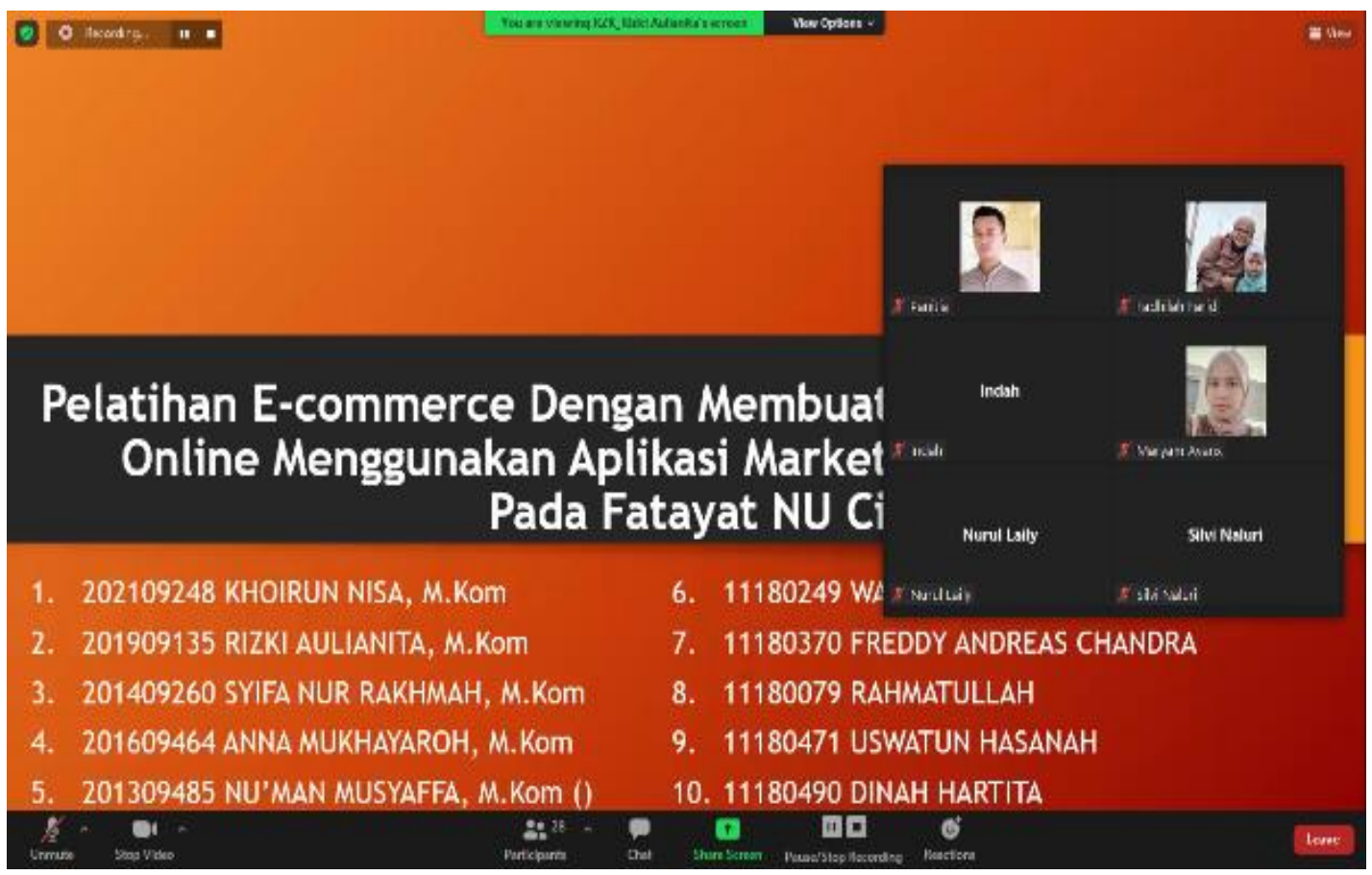

Sumber: Hasil Pelaksanaan (2021)

Gambar 4. Pengabdian Kepada Masyarakat Melalui Zoom Meeting

Pada gambar 4 terlihat tutor pelatihan Ibu Rizki Aulianita, M.Kom bersama tim tutor, Ibu Anna Mukhayaroh, M.Kom, Ibu Syifa Nur Rakhmah, M.Kom, Bapak Nu'man Musyaffa, M.Kom sedang memberikan pelatihan melalui zoom meeting untuk membuat toko online menggunakan aplikasi marketplace pada Fatayat NU Ciledug kepada peserta.

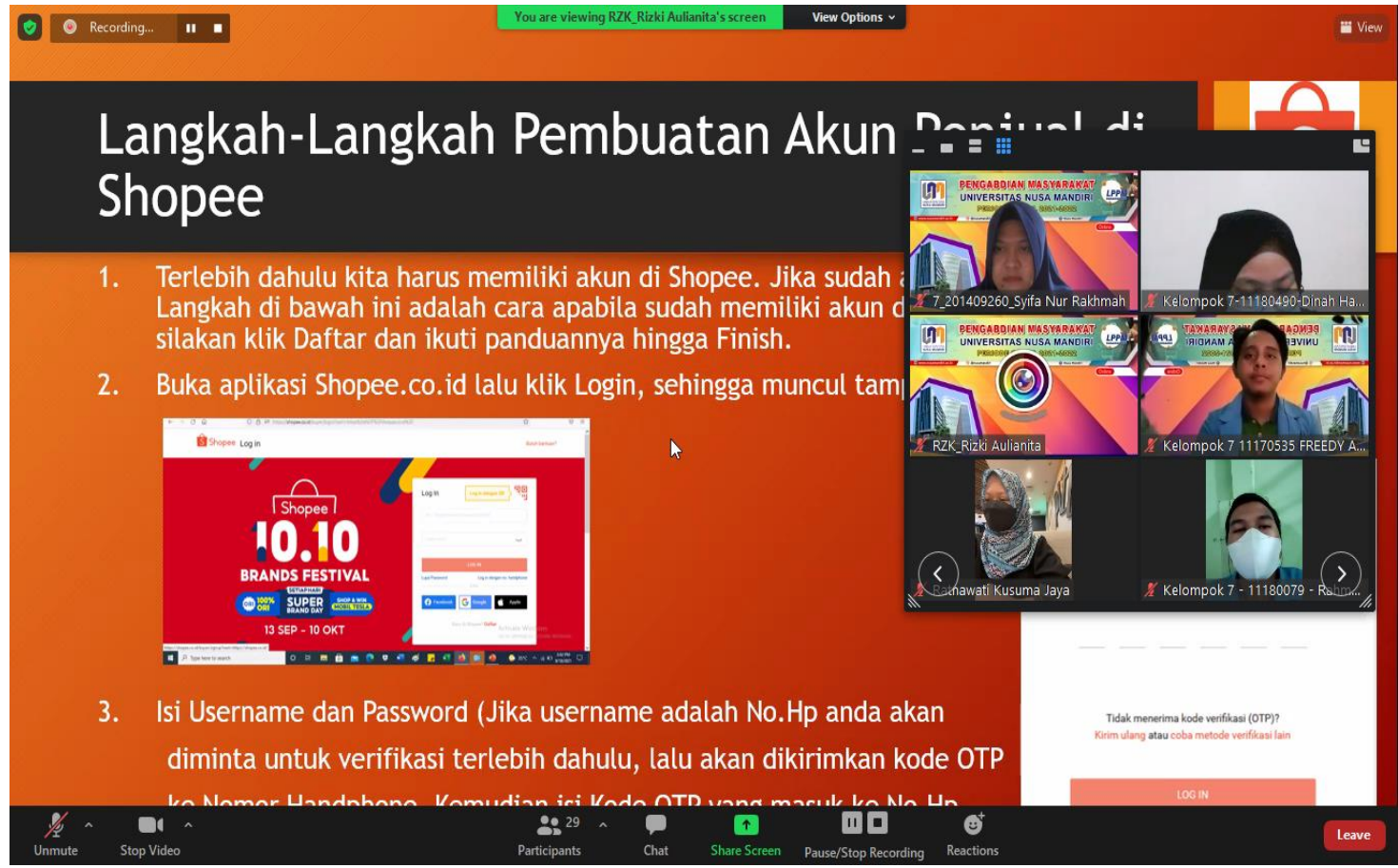

Sumber: Hasil Pelaksanaan (2021)

Gambar 5. Beberapa Kegiatan Fatayat NU Ciledug 
Gambar 5 menunjukkan antusiasme para peserta pelatihan membuat toko online menggunakan aplikasi marketplace pada Fatayat NU Ciledug. Peserta mendengarkan tim tutor menjelaskan tentang cara pembuatan akun pada marketplace sampai dengan proses transaksinya.

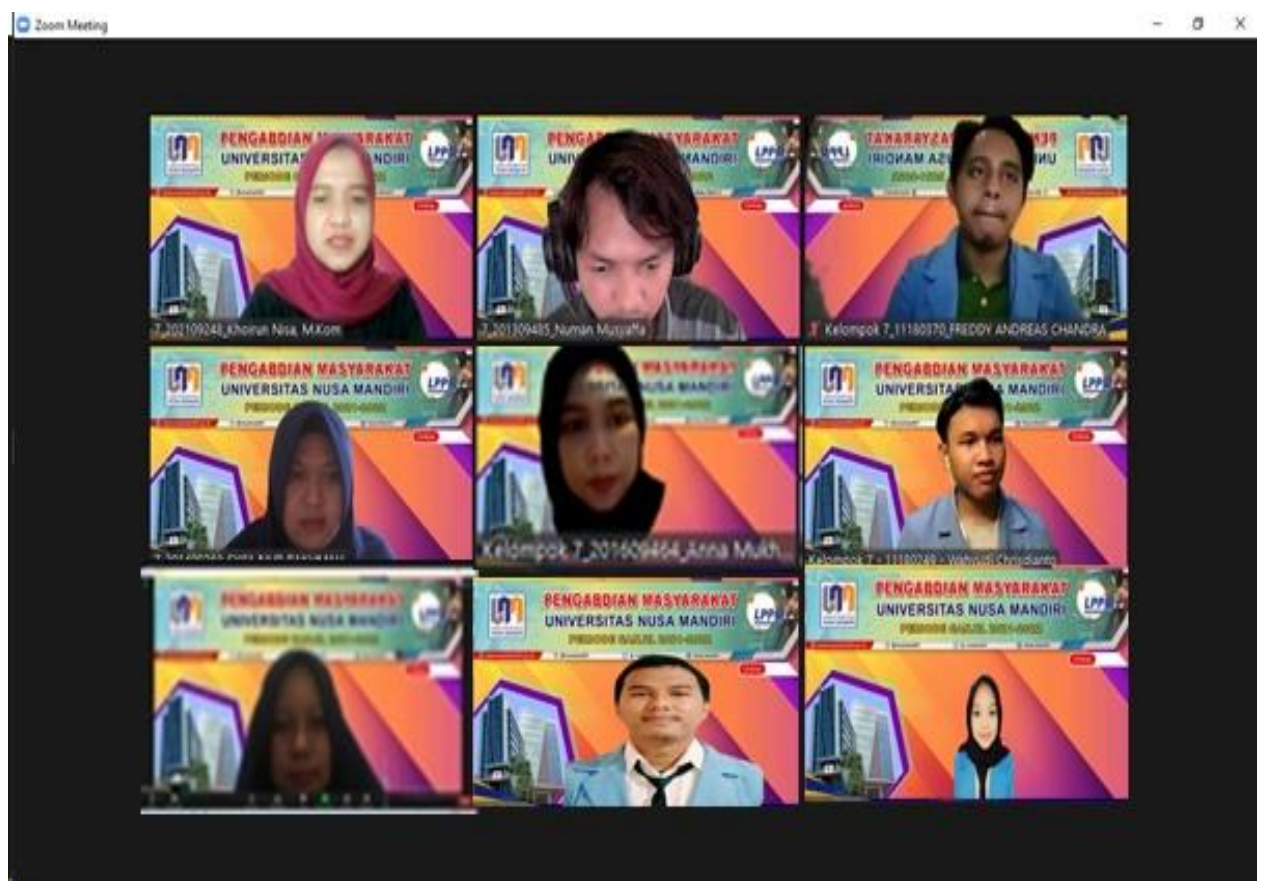

Sumber: Hasil Pelaksanaan (2021)

Gambar 6. Tim tutor dan mahasiswa Universitas Nusa Mandiri

Peserta pengabdian masyarakat sangat senang dengan adanya pelatihan membuat toko online menggunakan aplikasi marketplace oleh dosen Univeristas Nusa Mandiri. Kegiatan pengabdian masyarakat ini dapat terlaksana dengan baik dengan dukungan anggota Fathayat Nahdatul Ulama (NU) cabang Ciledug. Pelaksanaan kegiatan pengabdian kepada masyarakat ini berjalan dengan tertib, lancar tanpa ada kendala yang berarti.

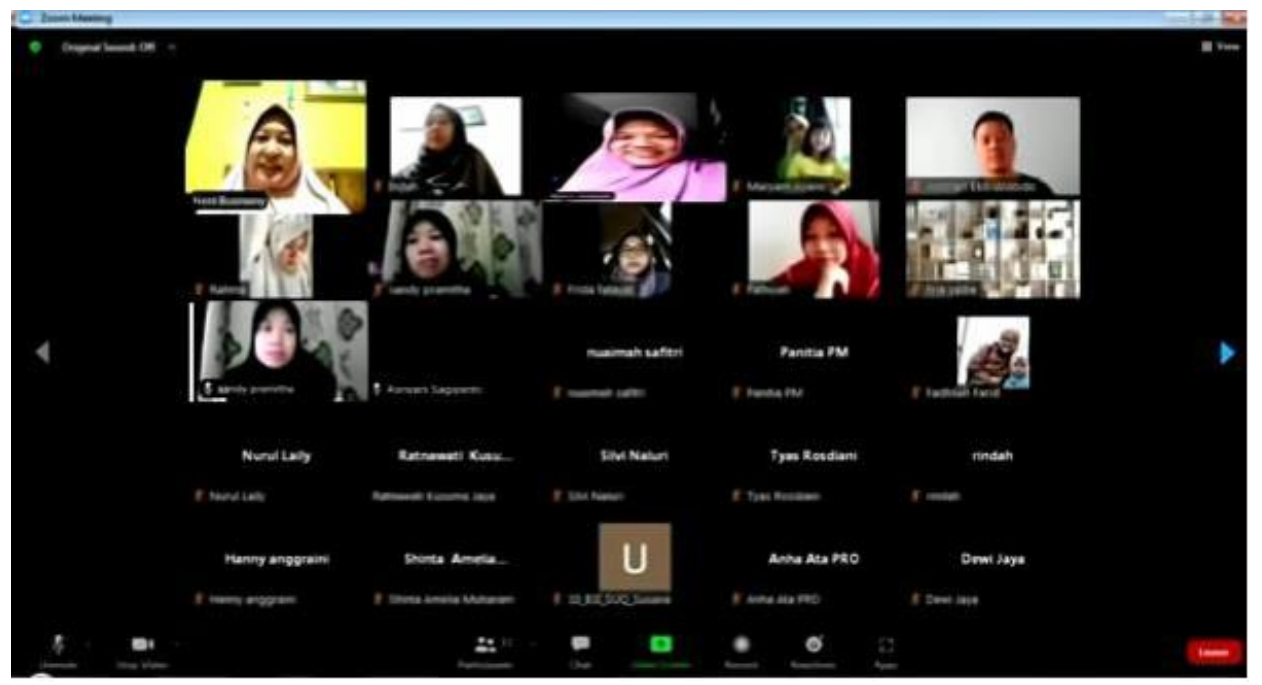

Sumber: Hasil Pelaksanaan (2021)

Gambar 7. Peserta pelaksanaan Pengabdian Masyarakat 


\section{Kesimpulan}

Berdasarkan kegiatan pengabdian masyarakat yang telah dilakukan, maka dapat disimpulkan beberapa hal diantaranya dengan adanya pengabdian kepada masyarakat ini sangat berguna sekali bagi pihak mitra sehingga dapat meningkatkan jaringan pemasaran usaha dagangnya. Kegiatan pengabdian masyarakat ini dapat memberikan wawasan dan ilmu pengetahuan dalam bidang TIK, khususnya dalam pembuatan toko online menggunakan market place yang ada. Memanfaatkan market place yang ada sebagai bentuk sarana promosi kepada publik atau masyarakat sehingga akan menarik penjualan ke masyarakat.

\section{Ucapan Terima Kasih}

Kami menyampaikan ucapan terima kasih kepada para anggota pengurus Fatayat NU Ciledug karena sudah bersedia menerima dan bersedia mengikuti pelaksanaan kegiatan pengabdian masyarakat ini dengan sangat antusias. Begitu juga kepada seluruh pimpinan, dosen dan juga mahasiswa Universitas Nusa Mandiri yang telah memberikan dukungan bagi kami dalam melaksanakan salah satu dharma perguruan tinggi melalui kegiatan pengabdian kepada masyarakat.

\section{Daftar Pustaka}

Hasyim, M. (2002). Merakit Negeri Berserakan. Surabaya: Yayasan 95.

I.K.A.Purnawan. (2016). Pelatihan Implementasi E-Commerce Untuk Menangkap Peluang Usaha Bagi Generasi Muda Di Kelurahan Kuta. Jurnal Udayana Mengabdi, 15(2), 107111.

Indonesia, D. R. P. kepada M. U. (2011). Panduan Pengajuan Proposal Hibah Pengabdian kepada Masyarakat Universitas Indonesia. Jakarta: Universitas Indonesia.

Laudon, K., \& Laudon, J. P. (1998). Sistem Informasi Manajemen: The Digital Firm, International Edotion. New Jersey: Pentise Hall International Inc.

Levani, Prastya, \& Mawaddatunnadila. (2021). Coronavirus Disease 2019 (COVID-19): Patogenesis, Manifestasi Klinis dan Pilihan Terapi. Jurnal Kedokteran Dan Kesehatan, 17(1), 44-57. Retrieved from https://jurnal.umj.ac.id/index.php/JKK/article/view/6340

Merdeka. (2021). Belanja Online Meningkat saat Pandemi, Ini Daftar E-Commerce Paling Banyak Dikunjungi. Retrieved from https://www.merdeka.com/uang/belanja-onlinemeningkat-saat-pandemi-ini-daftar-e-commerce-paling-banyak-dikunjungi.html?page=2

Opiida. (2014). Pengertian E-marketplace. Retrieved from https://tokokhalista.wordpress.com/2014/04/18/pengertian-e-marketplace/

Pressmann, R. S. (2015). Softeware Engineering A Practitioner's Approach Seventh Edition. Strauss, J. and Frost, R. (2001). E-Marketing. Prentice-Hall, Upper Saddle River, NJ. 
Sukamto, R. A., \& Shalahuddin, M. (2018). Rekayasa Perangkat Lunak Terstruktur dan Berorientasi Objek. Bandung: Informatika Bandung. 